

\section{LEYES Y DECRETOS: UNA POSTURA ESTATAL EN LA CULTURA Y EN LA FORMACIÓN DE UN MERCADO DE ARTE EN COSTA RICA (1959-2005)}

Eugenia Zavaleta Ochoa

Historiadora del Arte. Investigadora del Centro de Investigación en Identidad y Cultural Latinoamericanas y profesora de la Escuela de Estudios Generales de la Universidad de Costa Rica. ezavalet@le.ucr.ac.cr 
A finales de la década de 1950, el Estado comenzó a promulgar leyes y decretos ejecutivos relacionados con el ámbito de la cultura, los cuales se convirtieron en la génesis de un armazón legal que configuraría los lineamientos de una política cultural por los próximos cuarenta y cinco años. Así, a medida que pasaban los años y los decenios, una normativa se enlazaba a una anterior hasta conformarse una red que contribuyó con el desarrollo de la labor creativa de los artistas, con el establecimiento de instituciones culturales y con la formación de un público que acogería la producción artística, por ejemplo; en otras palabras, se establecieron las condiciones que permitieron el desenvolvimiento de un mercado de arte en Costa Rica. Por consiguiente, en esta ponencia se analizarán las normativas de índole cultural, que se emitieron entre 1959 y el 2005.

\section{Asomos de apoyo estatal (1959-1969)}

En 1941, Ricardo Segura Méndez declaraba su disgusto por la situación artística que se vivía en el país, en un artículo publicado en la revista Vanguardia. Uno de sus reclamos lo expresó de esta manera: “...las clases [sic] administrativas en Costa Rica carecen de opinión respecto a cuestiones artísticas... Esta protesta se encauza a que no hay el menor asomo de apoyo hacia lo más auténtico de nuestra vida artística." Evidentemente, Segura percibía un vacío de aquello que en la década de 1980 llegaría a denominarse políticas culturales.

A finales de los años cincuenta y principios de los sesenta, el Estado empezó a participar en la promoción de la cultura en una forma más activa. La evidencia inobjetable es la creación de tres leyes relativas a la creación de la Editorial Costa Rica, los Premios Nacionales y la Dirección General de Artes y Letras. Con la formulación de la ley de creación de la Editorial Costa Rica ( No 2366) -en 1959-, comenzó a haber una política cultural estatal. ${ }^{2}$ Sin duda, en este momento, se empezó a estructurar y a desarrollar -en forma sistemática- una armazón legal para perfilar lo que sería el ámbito cultural de las siguientes décadas.

Si bien es cierto, esta ley estaba enfocada a apoyar y beneficiar a los autores costarricenses, en su formulación ya se percibe un interés por otros sectores y por promover, en general, la cultura. Así, se trasluce en su artículo $2^{\circ}$ : "La Editorial tiene como fin principal el fomento de la cultura del país mediante la edición de obras literarias, artísticas y cientificas de costarricenses

1 Ricardo Segura Méndez, "La pintura en Costa Rica”, Vanguardia (Costa Rica) 4 (octubre 1941): 8. Todo corchete es de la autora. Este artículo fue amablemente proporcionado por el historiador Iván Molina.

2 Rafael Cuevas Molina, Cultura y política en Costa Rica. Entrevistas a protagonistas de la política cultural en la segunda mitad del siglo XX (San José, Costa Rica: Editorial Universidad Estatal a Distancia, 2006), 48. 
y de extranjeros en casos de mérito especial.”3 Por lo tanto, se buscaba fomentar la cultura por medio no solo de obras literarias, sino también artísticas y científicas, o sea, abarcaba a un amplio rango de creadores, desde artistas hasta científicos de diversas disciplinas.

Esta ley se ocupó de establecer quién integraría la Editorial, se señalaba -por ejemplouna asamblea de autores. Esta incluía a diversos grupos que conformaban el sector cultural (escritores, artistas plásticos y científicos); es decir, no solo se tomaba en cuenta a los autores que podían producir publicaciones sobre los temas señalados, sino también a los creadores visuales. Así, el Estado daba los primeros pasos para aglutinar a los artistas de las diversas disciplinas creativas.

Con la ley de creación de la Editorial Costa Rica, los creadores visuales ya eran tomados en cuenta, aunque fuera un tanto en forma colateral; sin embargo, continuaban subestimados, pues -siendo esta una de las primeras leyes importantes para estimular el campo cultural- beneficiaba especialmente a los escritores, con la instauración de una editorial. Un nuevo incentivo lo propiciaría la Ley $\mathrm{N}^{\circ}$ 2901, que estableció el Premio “Aquileo J. Echeverría” en los siguientes campos: novela, cuento, ensayo, poesía, historia, teatro, música, pintura y escultura, según el artículo $2^{\circ}$. En el artículo $1^{\circ}$, se enunció la instauración del Premio Nacional de Literatura, que se denominó “Magón”, el cual sería otorgado “...a un escritor costarricense, como reconocimiento a su obra total hasta la fecha en que se conceda el premio."4

Cabe destacar que nuevamente hay una fuerte inclinación hacia el grupo de los escritores; primero, por orden de artículos se le da prioridad a estos con un premio que los privilegia y los hace despuntar entre los demás artistas y, segundo, en el siguiente artículo, se les dio preponderancia al enunciarlos con antelación a pintura y escultura, citados de últimos. Además, hay una diferencia significativa en el dinero en efectivo que se le asignó a cada galardón. Al "Magón", se le confirió la suma de ф16.000,00, mientras que al "Aquiles J. Echeverría”, se le otorgó un monto de $\$ 36.000,00$, que se dividiría proporcionalmente entre las obras premiadas, sin excederse los $₫ 8.000,00$ por pieza laureada.

En todo caso, el Estado había iniciado un proceso de estímulo general hacia las artes y, por consiguiente, hacia la creación visual; especialmente, esto se dio durante los gobiernos del

3 Oficial, Colección de leyes, decretos, acuerdos y resoluciones, I Semestre, I Tomo (San José, Costa Rica: edición oficial, Imprenta Nacional, 1959), 323. El destacado es de la autora.

$4 \quad$ Oficial, Colección de leyes, decretos, acuerdos y resoluciones, II Semestre, I Tomo (San José, Costa Rica: edición oficial, Imprenta Nacional, 1961), 680. 
Partido Liberación Nacional o gracias a iniciativas de intelectuales socialdemócratas (e.g. Alberto Cañas y Fernando Volio). El siguiente paso que se dio fue instaurar la Dirección General de Artes y Letras, como organismo adscrito al Ministerio de Educación Pública, de acuerdo con la Ley № 3088 (1963). El objetivo de la nueva entidad, según lo estipuló el artículo 1º era el siguiente: “...estimular, divulgar y extender la actividad artística y literaria del país, en todos sus aspectos y manifestaciones, y de defender el patrimonio artístico, cultural e histórico de la nación.”’ Por lo tanto, el propósito del Estado, por medio de Artes y Letras, era proteger la actividad artística y literaria, para lo cual organizaría concursos, exposiciones, festivales y giras, financiaría eventos relativos al arte, concedería becas y auspiciaría cursos e institutos de enseñanza artística, entre otras cosas. Al amparo de esta ley, las artes visuales experimentaron un fuerte incentivo.

Con la ley de creación de Artes y Letras, se le dio potestad a esta para regular y estimular la actividad artística del país; más aun, -en 1969- con la emisión de su reglamento ( $\left.\mathrm{N}^{\circ} 33\right)$, quedó más explícita su labor. Uno de los propósitos de sus tareas fue -justamente-estimular la creación artística y literaria (artículo $17^{\circ}$ ), para lo cual se le encomendó realizar cada año los Juegos Florales Centroamericanos, abiertos a los habitantes del Istmo. Estos consistieron en concursos relativos a tres ramas diferentes de las Artes y las Letras, que cada año variaban. El reglamento presentaba dos atractivos que podían incentivar la participación de los artistas; por un lado, tenían contenido monetario, es decir, por cada rama se otorgarían dos premios de $\$ 3.000,00$ y \$1.500,00 y, por otro lado, el jurado de estos certámenes serían personalidades de reconocidos méritos (artículo $19^{\circ}$ ), lo que implicaba prestigio y legitimación para el ganador. Poco a poco se pretendía abrirles un espacio a los artistas y, a su vez, destacarlos en la sociedad al darles renombre y reputación con dichas distinciones.

Otra vía de estímulo y distinción fue el establecimiento de las Becas Taller (artículo $27^{\circ}$ ). $\mathrm{Su}$ fin era brindar una ayuda económica -un máximo de $\not 1.000,00$ mensuales- a escritores y artistas para que se dedicaran a la creación literaria, musical y plástica, durante seis meses con posibilidad de ampliarse por un plazo igual. De esta forma, las leyes de creación de la Editorial Costa Rica, los Premios Nacionales y la Dirección General de Artes y Letras se convirtieron en la estructura de estímulo y reconocimiento para sacar a la luz a los artistas y hacerlos visibles en la sociedad. A partir de esta base legal, se comenzaría un proceso de mecenazgo y difusión de las artes visuales.

\footnotetext{
5 Base de datos Sistema Costarricense de Información Jurídica. http://www.pgr.go.cr/scij/
} 


\section{Detonan soportes jurídicos para la cultura (1970-1979)}

Las leyes y decretos emitidos en los años sesenta representaron el detonante que desencadenó una legislación más consistente en relación con el campo artístico. Así, en la década de 1970, se empezó a perfilar claramente el desarrollo de los cimientos que estructurarían y conformarían el ámbito artístico en los siguientes años. Básicamente, cuatro soportes jurídicos, que asumió el Estado, fueron fundamentales. Uno consistió en avalar leyes que permitieron la instauración de instituciones necesarias para la promoción artística y otro se basó en establecer normas para las edificaciones que albergarían estas instancias. El tercero consistió en establecer los presupuestos e impuestos con los que se financiarían dichas entidades y el cuarto residió en fomentar los gérmenes que conducirían al impulso inicial de la consolidación de un mercado de arte. Este marco legal contribuiría a que los artistas emergieran y destacaran en una sociedad que los ignoraba.

En 1971, se decretó la creación del Ministerio de Cultura, Juventud y Deportes con la Ley $N^{\circ}$ 4788. El escritor y exdiputado Alberto Cañas reconstruyó la génesis de este así: “....ahí fue -sesenta y tres, sesenta y cuatro cuando surgió la idea de que ya con una editorial, con un sistema de premios, ya se podía empezar a pensar en un Ministerio...” ${ }^{\text {}} \mathrm{Al}$ nuevo ministerio, se le encomendó lo siguiente en el artículo $2^{\circ}$ :

“...asumirá las responsabilidades, ingerencias y funciones que la ley señala al Ministerio de Educación Pública en relación con la Dirección General de Artes y Letras, la Dirección General de Educación Física y Deportes, la Editorial Costa Rica, el Museo Nacional, la Orquesta Sinfónica Nacional, los Premios Nacionales Magón, Aquiles J. Echeverría y Joaquín García Monge...”7

Aunque los artistas ya podían sentirse respaldados con el Ministerio de Cultura, tuvieron que esperar seis años para contar con una institución que se encargara única y específicamente de la creación artística, es decir, un museo de arte.

En 1977, se fundó el Museo de Arte Costarricense con la Ley Nº 6091, normativa que -además- lo respaldó y posicionó como el ente rector del arte costarricense. Así, lo determinó el artículo $1^{\circ}$ y evidenció la anterior disposición, al igual que el artículo $2^{\circ}$ y $3^{\circ}$, en donde se procuró cubrir todas las funciones relacionadas con la creación artística. Especialmente, se pueden destacar $6 \quad$ Cuevas, 50.

$7 \quad$ Base de datos Sistema Costarricense de Información Jurídica. 
dos. Una le asignaba la potestad de determinar cuáles son las obras más importantes de las artes plásticas costarricenses. Su otro cometido fue redactado en estos términos: “...propiciará la investigación y la divulgación de los valores artísticos costarricenses...”; o sea, sería la entidad que establecería cuáles eran las cualidades más importantes del arte costarricense, así como sus significaciones. En definitiva, el Museo de Arte Costarricense era la institución que definiría cómo es el arte costarricense y qué obras y artistas reunían las condiciones para ser incluidos y reconocidos en el campo de la creación artística.

Una previsión que realizó el Estado consistió en asegurarse edificaciones en donde ubicaría instituciones como los museos que estaba instaurando. El primer paso cardinal fue la emisión de la Ley Nº 5397, en 1973. En esta, se hizo la siguiente exigencia en el artículo 3: "La declaratoria que el Poder Ejecutivo haga mediante un decreto, de que determinada edificación de propiedad pública es de interés histórico, arquitectónico o cultural, implicará una prohibición total de demolición...” Así, se aseguraba espacios que más adelante utilizaría. Efectivamente, en la ley de fundación del Museo de Arte Costarricense ( $\mathrm{N}^{\circ}$ 6091) se hizo posesión de uno de esos edificios patrimoniales, que posteriormente serían declarados de interés histórico, tal como se dispuso en el artículo 11": "Transfiérase al Museo de Arte Costarricense el edificio del antiguo Aeropuerto de La Sabana, que actualmente ocupa la Dirección General de Deportes..." ${ }^{10}$ Posiblemente, se consideró más apropiado ubicar un museo de arte -símbolo de prestigio de la alta cultura- en un edificio de las calidades arquitectónicas del antiguo aeropuerto, a que ese espacio siguiera ocupado por una entidad deportiva.

En 1979, el Museo Histórico Cultural Juan Santamaría -fundado en 1974, bajo la Ley $\mathrm{N}^{0}$ 5619- también encontró residencia en una edificación de interés cultural; así, se acordó en el artículo $1^{\circ}$ del Decreto Ejecutivo Nº 9951-C: "Declarar reliquia de interés arquitectónico, el inmueble que albergara la Cárcel de Alajuela y que en lo futuro será sede del Museo Histórico Cultural Juan Santamaría de Alajuela."11 Un edificio más que se sumó al mismo propósito fue la antigua casa de habitación del ex presidente Rafael Ángel Calderón Guardia, la cual fue declarada Monumento Nacional con la Ley $\mathrm{N}^{\circ} 6377$ y convertida en museo.

De esta forma, los museos recién fundados encontraban un lugar de carácter patrimonial

$8 \quad$ Oficial, Colección de leyes, decretos, resoluciones y acuerdos, II Semestre, III Tomo (San José, Costa Rica: edición oficial, Imprenta Nacional, 1977), 927.

$9 \quad$ Base de datos Sistema Costarricense de Información Jurídica.

$10 \quad$ Ibid.

11 Oficial, La Gaceta, 8 de mayo 1979, 2. 
y de propiedad pública en donde ser ubicados. En el caso de estos dos últimos museos, ambos -más tarde- habilitaron salas de exhibición, en las que se montarían exposiciones de obras de arte, con lo que contribuirían a divulgar y promocionar la creación artística y, en consecuencia, a incentivar el mercado de arte.

Para sostener y financiar las nuevas instituciones comprometidas con la cultura, el Estado también se apoyó en soportes legales para asegurarse su funcionamiento. En el caso de las leyes de creación de dichas entidades, se introdujeron artículos en los cuales se indicaban los presupuestos con que contarían para sus gastos. El establecimiento de impuestos fue otro recurso utilizado por el Estado para financiar sus entidades culturales y las actividades que estas programaban. En 1975, la Ley $\mathrm{N}^{\circ} 5812$ (artículo $2^{\circ}$ ) gravó los espectáculos públicos en que se contrataban artistas extranjeros con “....un 10\% del valor de la contratación original, sus modificaciones y sus prórrogas." ${ }^{12}$ El destino del monto recaudado debería ser utilizado por el Ministerio de Cultura, Juventud y Deportes para promover actividades artísticas. Posteriormente, esta disposición fue reformada por el artículo $14^{\circ}$ de la ley de creación del Museo de Arte Costarricense, en donde se estipulaba que esta institución recibiría lo recaudado por el impuesto a los espectáculos públicos.

Las leyes emitidas en la década de 1970 también le asignaron el papel de comprador de arte al Estado, lo cual implicaba que se promovería la creación artística. Particularmente, en 1973, se dio un énfasis especial con la promulgación de cuatro leyes que le permitirían al Estado convertirse en mecenas y, a la vez, incentivar el quehacer artístico al crearse las expectativas de un posible mercado de arte, así como conformar un patrimonio nacional con el que se realzaría a los artistas. Primero, se trabajó en cambiar la percepción hacia la creación y el patrimonio artístico, lo cual se evidencia en el Reglamento del Museo Nacional, emitido como decreto ejecutivo ( $\mathrm{N}^{\circ}$ 2812-C) en febrero de 1973. En el artículo $8^{\circ}$, se mencionaron las atribuciones de la Junta Administrativas, entre las que cabe destacar las señaladas en el inciso 2:

"Hacer cumplir las disposiciones de la ley [sic] No 7 de [sic] 6 de octubre de 1938, o de las modificaciones que de ella se hagan, o de nuevas leyes sobre protección y conservación del patrimonio cultural, arqueológico, artístico o científico del país, ejerciendo las funciones y atribuciones que las leyes encarguen a las autoridades y

12 Oficial, Colección de leyes, decretos, acuerdos y resoluciones, II Semestre, II Tomo (San José, Costa Rica: edición oficial, Imprenta Nacional, 1975), 908. 


\section{a la Dirección del Museo.”13}

En el apartado, se manifiesta un sentido más amplio e inclusivo del patrimonio que el expresado en el Reglamento del Museo Nacional de 1953, según Decreto Ejecutivo No 10, artículo $8^{\circ}$, inciso 2; es decir, mientras que en el de 1973 se incluían los bienes culturales, artísticos y científicos, en el de 1953 estaban excluidos, pues solo contemplaba como patrimonio los objetos arqueológicos. En otras palabras, se hizo un mayor esfuerzo por favorecer el campo artístico para dignificarlo y encumbrarlo dentro de la sociedad costarricense.

Paralelamente, en febrero de 1973, se promulgó la Ley Nº 5176, que sería el antecedente de una ley más contundente en el cometido que había asumido el Estado como mecenas, es decir, la Ley de Estímulo a las Bellas Artes Costarricenses ( $N^{\circ}$ 6750, aprobada en 1982). Con la normativa de los años setenta, se inició un incentivo sistemático de un posible emergente mercado de arte. En el artículo $1^{\circ}$, se instó a las entidades públicas hacia ese camino:

"Facúltese al Gobierno Central, a las instituciones autónomas, semiautónomas y a las municipalidades, para que de acuerdo con sus posibilidades económicas, en sus presupuestos anuales de inversiones consignen partidas para promover la literatura, las artes nacionales, monumentos nacionales, adquirir piezas arqueológicas y obras de arte de autores nacionales..."14

Asimismo, se comenzó a definir la idea de disponer un porcentaje para la adquisición de creaciones artísticas, cuando se construyeran edificios estatales. Meses más tarde de haberse emitido esta normativa, o sea, en julio, se promulgó la ley con la que se regularían las funciones de la Dirección General de Artes y Letras (Ley N 5244). En el artículo $7^{\circ}$, se le encomendó y se precisó una de sus funciones de la siguiente manera:

"Será función específica de la Dirección el adquirir obras de arte para que formen parte del patrimonio público y eventualmente figuren en la colección artística del Museo Nacional. Igualmente, la Dirección tendrá funciones consultivas respecto a las otras instituciones del Estado que se propongan adquirir obras artísticas.”"15

13 Oficial, Colección de leyes, decretos, acuerdos y resoluciones, I Semestre, I Tomo (San José, Costa Rica: edición oficial, Imprenta Nacional, 1973), 244-245.

$14 \quad$ Base de datos Sistema Costarricense de Información Jurídica.

15 Ibid. 
Finalmente, en octubre de 1973, se fijaron dos tributos más que seguían y fortalecían la iniciativa de convertir al Estado en un comprador de arte o, en definitiva, en un mecenas. Estos quedaron consignados en la Ley $\mathrm{N}^{\circ}$ 5351, cuyo primer artículo dispuso los montos y los artículos gravados:

"Se establece un impuesto de dos colones (\$2.00) sobre todo pasaje a cualquier lugar de la República, expedido por las empresas de aviación que trabajen dentro del territorio nacional. Asimismo, se establece un impuesto de cinco colones (\$5.00) por cada pasaje internacional emitido a título gratuito u oneroso, tanto que se expida en el país como en el exterior, para viajes que se originan en Costa Rica.”16

Ambos tributos serían cobrados por medio de un timbre con la inscripción "Museo Nacional”, el cual se pagaría y anexaría a cada boleto. La suma recolectada tendría como propósito la adquisición de piezas arqueológicas, artísticas y de valor histórico, adjudicación de becas, mejoras del plantel físico del Museo, gastos administrativos y creación de museos regionales, según el artículo $3^{\circ}$.

Durante la década de 1970, se comenzaron a evidenciar modificaciones en la forma de percibir la creación artística. Un cambio significativo se aprecia en las reformas que se manifestaron en las leyes relativas al Premio Nacional "Magón” y al Premio “Aquileo J. Echeverría”. El primero, como ya se había mencionado, fue creado para galardonar la obra total hasta la fecha de un escritor costarricense (Ley $\mathrm{N}^{\circ}$ 2901, emitida en 1961). Sin embargo, en 1971, la Ley $\mathrm{N}^{\circ}$ 4817 dio un salto cualitativo en la formulación del artículo $1^{\circ}$, que definía quiénes podían ser los aspirantes al Premio Nacional "Magón”:

"Se crea el Premio Nacional de Cultura que se denominará "Magón” que será otorgado anualmente a un escritor, artista o científico costarricense, en reconocimiento a la obra que lleve realizada en el campo de la creación o la investigación hasta la fecha en que se conceda el premio.” ${ }^{17}$

Es decir, ya no solo iban a ser reconocidos los escritores por su labor literaria de toda una vida, sino también los artistas y científicos tenían la oportunidad de ser distinguidos, pues ahora

16 Oficial, Colección de leyes, decretos, resoluciones y acuerdos, II Semestre, II Tomo (San José, Costa Rica: edición oficial, Imprenta Nacional, 1973), 786.

17 Base de datos Sistema Costarricense de Información Jurídica. 
se les consideraba merecedores de este premio. Así, estos sectores de intelectuales, especialmente los artistas, habían logrado ascender de rango en la jerarquía cultural.

En cuanto al Premio Nacional “Aquileo J. Echeverría”, la Ley N 2901 hacía mención de la pintura y la escultura como expresiones artísticas consideradas para otorgarles el premio. En la Ley $\mathrm{N}^{\circ} 4817$ (1971), ambas manifestaciones se cambiaron por el término de artes plásticas, con lo cual se amplió la posibilidad de que se juzgaran otras creaciones visuales. Por lo tanto, se tomaban en cuenta más expresiones artísticas, lo cual implicaba reconocer y legitimar más artistas visuales.

\section{El Estado se mantiene como protector de las artes (1980-1989)}

Durante la década de 1980, la creación de museos -especialmente- regionales fue un rasgo característico de la legislación que se promulgó en relación con aspectos culturales del país. El establecimiento de este tipo de museos se vio amparado con la instauración de la Dirección General de Museos con el Decreto Ejecutivo No 14844-C, emitido en 1983. Dicha entidad se encargaría de dictar las políticas convenientes para crear museos en el país (artículo $2^{\circ}$ ). Entre 1983 y 1989, se promulgaron al menos nueve decretos ejecutivos y leyes orientados hacia la instauración de museos, de los cuales siete tenían un sentido regional. Una de las funciones de la Dirección sería darle asistencia técnica a estos museos, mientras que las fundaciones y asociaciones se encargarían de su administración ${ }^{18}$ es decir, el Estado comenzaba a evidenciar intentos por liberarse del sustento económico de ciertas instituciones.

El énfasis que le dio la Ministra de Cultura, Juventud y Deportes, Marina Volio (19781982), a su gestión, es decir, hacia la identidad nacional, la cultura popular y la descentralización de las actividades culturales, representó un impulso significativo para provocar la creación de estos museos, después de haber ya finalizado su cargo. Si bien es cierto, las políticas culturales gubernamentales tomaron dicha orientación, así como un corte liberal, en donde la preocupación era restringir la participación del Estado y ahorrarse costos “innecesarios” generados por la filosofía paternalista del Partido Liberación Nacional, ${ }^{19}$ días antes de concluir la labor de Volio como ministra, se aprobaron dos normativas con las que se fortalecía al Estado en su calidad de mecenas y protector de las artes. En la Ley $\mathrm{N}^{\circ} 6750$ (1982), destaca el artículo $7^{\circ}$, pues este 18 María del Pilar Herrero Uribe, Los museos costarricenses: trayectoria y situación actual (San José, Costa Rica: Dirección General de Museos, Ministerio de Cultura, Juventud y Deportes, 1997), 53.

19 Rafael Cuevas Molina, El punto sobre la i. Políticas culturales en Costa Rica (1948-1990) (San José, Costa Rica: Editorial de la Dirección de Publicaciones del Ministerio de Cultura, Juventud y Deportes, 1995), 203-204. 
impulsaría al Estado a convertirse en un fuerte coleccionista de arte. Dicho apartado se redactó así:

"Cuando el Estado o sus instituciones proyecten la construcción de un edificio público, para la prestación de servicios directos a la población, cuyo costo sobrepase los diez millones de colones, el Ministerio de Cultura, en coordinación con la institución correspondiente, deberá señalar, antes de la aprobación definitiva de los planos y presupuestos, el porcentaje mínimo de éstos que se dedicará a la adquisición o elaboración de obras de arte. La Contraloría General de la República no aprobará presupuestos de construcción de edificios públicos, sin el requisito anterior." ${ }^{20}$

Así, el Estado asumía el papel de comprador de arte, es decir, de creaciones artísticas consideradas de la alta cultura y no de la cultura popular, lo cual implicaba el fomento de un mercado de arte. Asimismo, se buscó proteger e incentivar a los artistas en su producción con las estipulaciones planteadas en los artículos $2^{\circ}$ y $6^{\circ}$. En el primero, se señaló que tanto las obras de los artistas nacionales como la de los extranjeros residentes en el país no serían gravadas con tributos de exportación, importación, ventas, consumo ni tasas aduaneras. En el segundo artículo mencionado, se dispuso que los materiales requeridos para la creación de obras de arte estarían exentos de impuestos y de tasas aduaneras, siempre y cuando dichos materiales fueran importados por cooperativas de artistas y el Ministerio de Cultura para ser vendidos a sus asociados.

La Ley N 6750 también estimó la forma de reunir fondos para que los museos estatales pudieran adquirir obras. Así como se exoneró de impuestos a las creaciones artísticas con determinadas especificaciones, otras - en cambio- tendrían una carga tributaria, según lo indicaba el artículo $8^{\circ}$. Este era el caso de grabados con ediciones superiores a los cien ejemplares, de pinturas y esculturas con un número mayor de seis copias y de las reproducciones industriales de arte, puesto que estas eran consideradas como labor industrial y comercial y, por ende, sujetas a tributación. Al final de este artículo, se determinó que el destino de dichos gravámenes sería para el mantenimiento y adquisición de obras de los museos.

Además de estimular a los artistas, la Ley 6750 pretendía incentivar a los coleccionistas y posibles donadores de arte a adquirir obras artísticas, dados los beneficios que podrían obtener con esta acción. En el artículo $4^{\circ}$, se estableció lo siguiente: “Todo propietario de una obra de 20 Oficial, Colección de Leyes y decretos, I Semestre, I Tomo (San José, Costa Rica: edición oficial, Imprenta Nacional, 1982), 204. 
arte, de un artista costarricense, o de un extranjero residente en el país, podrá deducir el diez por ciento de su valor, del monto imponible del impuesto sobre la renta...”21 Sin embargo, debían cumplir con dos requisitos; uno consistía en que la obra debía haber sido expuesta en un museo estatal durante todo el año relativo al período del tributo que se deduciría, y el otro requerimiento residía en que el Ministerio de Cultura debía certificar que el monto por deducir correspondía al valor comercial que la obra tuvo en el período aludido. En esta misma línea, el artículo $5^{\circ}$ se dirigió a los donadores: "La donación de una obra de arte a un museo estatal, permitirá al donante deducir su valor del monto imponible del impuesto sobre la renta. Para estos efectos, el Ministerio de Cultura será el encargado de certificar el valor comercial de la obra de arte."22

Justamente, esta ley se denominó Ley de Estímulo a las Bellas Artes Costarricenses por los incentivos que pretendía brindar; así, motivaría a los artistas en su creación al ser sus obras adquiridas tanto por coleccionistas privados como públicos, y a los compradores de arte, pues sus adquisiciones implicaban deducciones de impuestos, como también a los museos estatales, ya que contarían con obras para ser expuestas temporalmente y con otras que ingresarían permanentemente a sus acopios. En última instancia, dentro de este marco de expectativas favorables, el motor que se impulsaba era el desarrollo del mercado de arte en el país.

La otra normativa de 1982, que robustecería al Estado como mecenas y protector de las artes, fue el Decreto Ejecutivo No 13600-C-G, designado "Reglamento a la Ley que Establece un Impuesto a la Presentación de Artistas Extranjeros del Espectáculo a Favor del Museo de Arte Costarricense”. En este caso, el interés fue dejar establecido un reglamento relativo a la Ley $\mathrm{N}^{\circ}$ 5812 de 1975, en la que se gravaba la presentación de artistas extranjeros del espectáculo con un tributo destinado al Museo de Arte Costarricense. ${ }^{23}$ Con dicho reglamento se pretendía regular y hacer acatar -en forma estricta- la antes mencionada ley. Sin duda, esto evidencia un interés, por parte de los gobernantes del momento, por hacer cumplir una ley que fortalecería una institución estatal para -así- desarrollar su cometido de entidad rectora del arte nacional; en otras palabras, el Estado continuaba y fortalecía su papel de protector del arte.

21 Oficial, Colección de Leyes y decretos, I Semestre, I Tomo (San José, Costa Rica: edición oficial, Imprenta Nacional, 1982), 203.

$22 \quad$ Ibid.

23 El artículo $11^{\circ}$ de la Ley $\mathrm{N}^{\circ} 5812$ (1975) no estipuló específicamente que el gravamen a la presentación de artistas del espectáculo era a favor del Museo de Arte Costarricense; sin embargo, en la ley de creación de esta institución (1977) dicho artículo se reformó al establecerse que el Museo de Arte Costarricense recibiría lo recaudado por el impuesto a los espectáculos públicos. 
Un reglamento más que firmaron el presidente Carazo y la ministra Volio fue el de la Escuela Casa del Artista (Decreto Ejecutivo No 12004-C), en 1980. Este señalaba que dicha institución era una dependencia del Ministerio de Cultura, Juventud y Deportes, cuyo objetivo era promover y difundir las artes plásticas. Además, indicaba que sus fondos provenían fundamentalmente de la subvención anual de la Ley de Presupuesto. ${ }^{24}$ Es decir, el Estado se mantenía como un ente protector del quehacer artístico. Esta disposición permanecía aún en 1989, cuando el entonces presidente de la República, Oscar Arias, y su Ministro de Cultura, Carlos Francisco Echeverría, derogaron dicho reglamento, pero enfatizaron el mantenimiento de la injerencia estatal en la Escuela Casa del Artista al encargarse de su funcionamiento y financiamiento.

Así, las entidades gubernamentales proseguían inmiscuidas en las principales instituciones artísticas radicadas en la capital, por medio de las cuales alcanzaban a diferentes sectores de la sociedad. Si la Escuela Casa del Artista beneficiaba a los estratos sociales de escasos recursos, según lo estipuló el considerando $2^{\circ}$ del Decreto Ejecutivo N$^{\circ}$ 18913-C, se puede deducir que el Museo de Arte Costarricense ya se ocupaba de su contraparte, los grupos cultos y privilegiados del país.

A finales de la década de 1980, se promulgaron dos reglamentos que condujeron a reforzar directa y específicamente la entidad enfocada hacia el arte, es decir, el Museo de Arte Costarricense, y -en alguna medida- a estimular la venta de obras. Uno de estos fue el Reglamento a la Ley de Estímulo a las Bellas Artes Costarricenses № 6750 (Decreto Ejecutivo No 18215-C-H), emitido en 1988. En realidad, esta normativa era muy similar a la Ley $\mathrm{N}^{\circ} 6750$, prácticamente los artículos eran los mismos; la diferencia entre ambas residía en cambios de redacción y en la incorporación de especificaciones más precisas y detalladas.

Si bien es cierto que existía la intención de estimular a los artistas con esta ley, el trasfondo parecía ser otro. El país vivía procesos económicos y sociales generados por la implantación de los Programas de Ajuste Estructural (PAE). En relación con estos, entidades como el Fondo Monetario Internacional (FMI) y la Agencia Internacional para el Desarrollo (USAID) determinaron directrices para asignar recursos al país, tales como reducción del gasto público y de las tarifas a las importaciones, privatización de las empresas estatales y la promoción de las exportaciones no tradicionales y de la banca privada. ${ }^{25}$ Dentro de este contexto, el Reglamento a

24 Cfr. Oficial, Colección de leyes y decretos, II Semestre, III Tomo (San José, Costa Rica: edición oficial, Imprenta Nacional, 1980), 599.

25 Iván Molina y Steven Palmer, Historia de Costa Rica. Breve, actualizada y con ilustraciones (San José, 
la Ley de Protección a las Artes Plásticas N ${ }^{\circ} 6750^{26}$ (Decreto Ejecutivo No 18215-C-H) asumía la mampara de apoyo a los artistas, pues -por un lado- prácticamente no existían grupos de artistas organizados que solicitaran la importación de materiales exentos de impuestos y -por otro ladosi surgía alguno, la gestión para hacer efectiva la exoneración era tan engorrosa que posiblemente los artistas desistirían de realizar la gestión. Así, el Estado se presentaba como protector de los creadores e incidentalmente -si se diera el caso- se evadiría la importación de productos con bajos aranceles, que representaban una merma en los fondos públicos y un incremento del déficit comercial del país. ${ }^{27}$

Esta velada oposición a las imposiciones de los organismos financieros internacionales se hace más evidente y audible en el artículo $9^{\circ}$ de la normativa antes mencionada. A pesar de los lineamientos dispuestos para disminuir el gasto público, el gobierno del presidente Oscar Arias (1986-1990) firmó un reglamento en que se contravenía dicha disposición al incurrir en erogaciones con la adquisición de obras de arte. Esta determinación era básicamente la misma que se indicaba en la Ley de Estímulo a las Bellas Artes Costarricenses, promulgada en 1982. En otras palabras, se enfatizaba y ratificaba lo señalado por esta ley, pero -además- se hacía hincapié en incluir especificaciones sobre los porcentajes que deberían gastarse en obras de arte, según el costo de construcción del edificio erigido.

Otras normativas que tienen antecedentes en las décadas anteriores se referían a los tributos relacionados con el gravamen a los pasajes nacionales e internacionales, tal era el caso de las Leyes $\mathrm{N}^{\circ} 831$ (1946), $\mathrm{N}^{\circ} 4370$ (1969) y No 5351 (1973). Mientras que en esta última el monto recaudado por concepto de impuesto a pasajes nacionales e internacionales se destinaba solo al Museo Nacional de Costa Rica, en la Ley No 6828 -promulgada en 1982- los beneficiarios se ampliaron: el Museo Nacional recibiría un 60\% y los demás museos estatales un 40\%. Además, el tributo por pasaje internacional se incrementó de $\$ 2,00$ a $\$ 50,00$. Un aumento posterior se determinó en el Decreto Ejecutivo № 18667-C (1988), el monto ascendía a \$100,00. Nuevamente, se estipuló que dicha suma debía de ser compartida con más museos, específicamente los museos

Costa Rica: Editorial de la Universidad de Costa Rica, 1997), 102-103.

$26 \quad$ Este reglamento aparece así denominado en La Gaceta y en la Colección de leyes, decretos y reglamentos y no como Reglamento a la Ley de Estímulo a las Bellas Artes Costarricenses, según se consignó anteriormente en relación con la ley N ${ }^{\circ}$ 6750. Cfr. Oficial, La Gaceta, 15 de julio 1988, 2-3. Oficial, Colección de leyes, decretos y reglamentos, II Semestre, I Tomo (San José, Costa Rica: edición oficial, Imprenta Nacional, 1988), 55-57.

27 Molina y Palmer, 108. 
regionales, los cuales recibirían un 15\%. En realidad, durante los años de 1980, se manifestó un interés por continuar y -sobre todo- consolidar los logros alcanzados gracias a las normativas que se promulgaron en la década anterior.

\section{Por momentos el Estado Benefactor se retrae (1990-1999)}

Al igual que en el decenio precedente, los años de 1990 tuvieron como rasgo característico la fundación de museos. Si en los años de 1980 se estableció una cantidad considerable de museos, en la siguiente se multiplicaron. En todos los decretos ejecutivos de creación de estas instituciones con excepción de dos (Museo Costarricense de la Comunicación Social y Museo Latinoamericano de Arte y Diseño Contemporáneo), se manifestó un interés explícito por basar la justificación de su fundación en aspectos relativos al patrimonio cultural y natural costarricense, la identidad nacional y la alteración de la cultura costarricense por la imposición de modos culturales foráneos, por ejemplo. ${ }^{28}$

La anterior orientación de los museos creados en la década de 1990 quedó excluida en el Museo Latinoamericano de Arte y Diseño Contemporáneo, establecido en febrero de 1993 por el Decreto Ejecutivo $\mathrm{N}^{0}$ 21831-C. Este fue creado con una visión más cosmopolita y globalizadora. El primer aspecto que se debe destacar es su denominación, Museo Latinoamericano de Arte y Diseño Contemporáneo; en otras palabras, era un museo que trascendía las fronteras costarricenses, no iba solamente a circunscribirse al territorio nacional para recuperar, conservar y estudiar una parte (o sea, las artes visuales) del patrimonio del país. En los objetivos de su creación, quedaba clara dicha intención.

"-Contribuir al desarrollo de la sociedad costarricense y latinoamericana por medio de la promoción y difusión del arte y el diseño.

-Promover la realización de talleres especiales, para el mayor entendimiento del arte y diseño universal.

-Procurar reunir y exhibir las obras de arte y diseño.

-Establecer contactos e intercambios con otros museos e instituciones similares en el mundo.

-Propiciar la investigación y la divulgación del arte y diseño universal, enfatizando los valores latinoamericanos." 29

28 La justificación antes mencionada no se da en relación con el Museo Costarricense de la Comunicación Social, pues este fue creado como una iniciativa del Colegio de Periodistas de Costa Rica y no del Estado. En el caso del Museo de Arte y Diseño Contemporáneo, más adelante se analizará por qué se evadió sustentarse en los razonamientos en que se basaron los demás museos.

29 Oficial, La Gaceta, 5 de febrero 1993, 4. El destacado es de la autora. 
Solo en el primer objetivo se hace alusión directa al país en el sentido de que sus habitantes se desarrollaran gracias a la promoción y difusión del arte y del diseño, pero sin especificar la procedencia de estos dos. La consciente omisión a este detalle queda clara en el tercer objetivo. No se hizo referencia alguna que indicara interés por preservar un patrimonio considerado base de la identidad nacional, tal como lo señalaban los museos creados en la década de 1990. En realidad, lo que se buscaba era que el público comprendiera el arte y el diseño universal, de acuerdo con el segundo objetivo. Además, se ubicó en primer lugar la investigación del arte y diseño universal, y luego el énfasis de lo latinoamericano. La intención era convertirse en un museo o institución similar a los existentes en cualquier parte del mundo globalizado. Así, el arte y el diseño contemporáneo quedan asociados al arte universal, no al arte que se hace en forma local como, por ejemplo, en Costa Rica. Posiblemente, lo contemporáneo rimaba más con una visión globalizadora del arte universal y no con las identidades culturales de los pueblos.

La anterior perspectiva se subrayó aun más con las modificaciones que sufrió el decreto ejecutivo de creación del Museo Latinoamericano de Arte y Diseño Contemporáneo. Pocos meses después de haberse publicado dicha normativa, apareció el Decreto Ejecutivo № 22261-C en La Gaceta, el cual hacía modificaciones a su antecesor. ${ }^{30} \mathrm{El}$ cambio se orientó hacia la eliminación de todas las alusiones relativas a lo latinoamericano; por ende, a partir de ese momento el nombre de la entidad sería Museo de Arte y Diseño Contemporáneo. De esta forma, se anuló la referencia regional e identitaria más cercana al país, es decir, lo latinoamericano, y se dejó la mención a lo universal. Consecuentemente, los objetivos del nuevo museo serían promover el entendimiento del arte y del diseño universal, así como propiciar su investigación y divulgación. En síntesis, prevalecía un interés por lo universal sobre lo regional y nacional.

En 1998, ya se promulgó como ley ( $\mathrm{N}^{\circ}$ 7758) la instauración del Museo de Arte y Diseño Contemporáneo. En su artículo $1^{\circ}$, se evidencia la intención de incorporar la visión-o al menos los términos- que había guiado el establecimiento de museos en la década de 1990. Aunque se aludía a vernáculo, diversidad cultural e identidad, su sentido queda ambiguo, pues no se especifica qué expresiones vernáculas y -sobre todo- de qué lugar, ni tampoco la diversidad cultural e identidad de quién; por lo tanto, puede ser la de cualquier país, región o pueblo, es decir, se

$30 \quad$ El Decreto Ejecutivo $N^{\circ}$ 21831-C, normativa con la que se creó el Museo Latinoamericano de Arte y Diseño Contemporáneo, fue publicado el 5 de febrero de 1993, en La Gaceta. El Decreto Ejecutivo No 22261-C, normativa con la que se le hicieron modificaciones al anterior decreto, apareció el 6 de julio de 1993, en La Gaceta. 
retorna a las referencias de arte universal de los dos decretos ejecutivos de creación del Museo. Esta concepción del Museo de Arte y Diseño Contemporáneo se acoge a la dinámica neoliberal que se vivía en la década de 1990, en donde lo nacional quedaba relegado y prevalecía una globalización y transnacionalización cultural. Precisamente, la entidad fue fundada durante una Administración -la del presidente Rafael Ángel Calderón (1990-1994) y su Ministra de Cultura, Aída Faingezicht- en que las políticas culturales se encauzaron hacia las "elites" pudientes; ${ }^{31}$ en otras palabras, se creaba un museo orientado hacia el arte contemporáneo universal, justo para aquellos grupos privilegiados con el que se les vincularía.

Otro rasgo que evidencia los tiempos neoliberales era la necesidad de buscar el apoyo de fondos privados y el soporte de fundaciones. El Estado Benefactor por momentos se retraía y, por ende, el mecenazgo que anteriormente había brindado a las actividades artísticas. Por eso, una institución como el Museo de Arte y Diseño Contemporáneo con el perfil ya analizado, incluía entre sus funciones la búsqueda de recursos privados y su director debía tener experiencia en la recaudación de este tipo de fondos.

Unos años antes, específicamente en 1993, se emitió la Ley No 7363, en la cual se promulgó el establecimiento de la fundación para administrar los Museos del Banco Central de Costa Rica. De acuerdo con el artículo $3^{\circ}$, los objetivos de la fundación eran primordialmente administrar y manejar los Museos del Banco Central de Costa Rica y, además, conseguir los recursos financieros para cumplir con los fines y objetivos de esta ley. Así, esta fundación asumía una parte importante de la gestión de dicha entidad.

Aunque había una fuerte política cultural por descentralizar y regionalizar, así como un impulso por liberar al Estado de sostener por completo los museos, se mantuvo la disposición de continuar con la creación de estos y con el patrocinio a los ya existentes, especialmente con los ubicados en la capital. Un caso es el Museo de Arte Costarricense, además de los dos anteriormente citados. En julio de 1999, se emitió el Decreto Ejecutivo No 27955-H, en el cual se determinó que al Museo se le exceptuaba del límite de gasto presupuestario definido en un decreto anterior y, su vez, se le fijaba un nuevo límite. Esta concesión se justificó en los considerandos por la necesidad de contar con más recursos para crear el Museo de Formas, Espacios y Sonidos (MUFES), entidad que estaría adscrita al Museo de Arte Costarricense. Pocos meses después,

31 Rafael Cuevas Molina, “Cultura y educación”, en Costa Rica contemporánea: raíces del estado de la nación, Juan Rafael Quesada, et al. (San José, Costa Rica: Editorial de la Universidad de Costa Rica, 1999), 253254. 
la Escuela Casa del Artista también se anexó al Museo. En el Decreto Ejecutivo No 27988-C -publicado en julio de 1999 en La Gaceta-, se definió que dicha Escuela se constituiría en un programa del Museo.

Mientras -en 1993- se creaba el Museo de Arte y Diseño Contemporáneo con una concepción que se vinculaba más con los sectores privilegiados, -en 1999- el Museo de Arte Costarricense -una institución más ligada con el arte producido en el pasado- tuvo la oportunidad de atraer a grupos minoritarios y sectores populares por medio de sus dos recién adscritas entidades, el MUFES y la Escuela Casa del Artista. El primero estaba dirigido hacia la población con discapacidad visual y la segunda hacia personas con limitación de tiempo libre, en otras palabras, personas de las clases trabajadoras o de "estratos sociales de escasos recursos", ${ }^{32}$ según se indicaba en el Decreto Ejecutivo $N^{\circ}$ 18913, emitido en 1989. De esta forma, pareciera que el Museo de Arte Costarricense trataba de hacer un balance entre el público al que debía divulgar y estimular las artes visuales, de acuerdo con su ley de creación ( $\mathrm{N}^{\circ} 6091$, artículo $1^{\circ}$ ), y el del Museo de Arte y Diseño Contemporáneo, que se vinculaba más con los grupos adinerados. En síntesis, se estableció una relación entre museo, su concepción y grupo al que se orientaba.

Cabe señalar -en todo caso- que la concepción del Museo de Arte Costarricense sufrió una modificación, en 1994. En este año, se publicó el Decreto Ejecutivo $\mathrm{N}^{\circ} 23643$, en el cual se le encomendaba el fomento de la actividad artística, en general; en otras palabras, el campo de acción del Museo se ampliaba, ya no sería un museo enfocado esencialmente hacia las artes visuales. Esta concepción se consolidó aun más cuando se reformó la normativa de creación del Museo por medio de la Ley N 7595 (1996), en donde se estipuló que la entidad se encargaría de las artes y la literatura costarricense. Una vez más se puede estimar que había una preeminencia por la labor literaria, pues esta disciplina no se dejaba de puntualizar en una ley que iba dirigida hacia el establecimiento de una institución de artes visuales.

El promotor de este cambio fue Alberto Cañas -intelectual ligado al ámbito de las letras y, entonces, diputado-, según lo manifestó en su columna "Chisporroteos”, publicada en La República: “...-en un plan de este diputado con el ministro Arnoldo Mora- se pretende darle la función [al Museo de Arte Costarricense] de gran caja chica del Ministerio que la Dirección de Artes y Letras tuvo hasta 1977...”33 Es decir, se hacía una reforma a la ley de creación del Museo de Arte Costarricense con criterios extrínsecos a la esencia de la institución y de sus requerimientos 32 Oficial, La Gaceta, 18 de abril 1989, 1.

33 Alberto F. Cañas, “Chisporroteos”, La República, $1^{\circ}$ de noviembre 1994, 19A. 
técnicos para facilitar y aumentar la gestión de otras entidades culturales y expresiones artísticas ajenas a esta.

En la década de 1990, se mantuvo la promulgación y reformas a leyes y decretos ejecutivos concernientes a los premios nacionales, exenciones fiscales y tributos, que fueron convenientes para al quehacer artístico y cultural. Aunque algunos tuvieron un carácter favorable, otros no; pareciera que se buscó establecer un balance entre estos dos tipos de normativas. En 1985, se había emitido la Ley $\mathrm{N}^{\circ}$ 6984, con la cual se pretendió proteger a las personas que se les había otorgado el Premio Magón. Así, se indicó en el artículo 1: "A toda persona galardonada con el Premio Magón, no protegida por ningún sistema de pensiones y carente de bienes inmuebles, salvo su casa de habitación, se le otorgará una pensión del Régimen no Contributivo de la Caja Costarricense de Seguro Social." ${ }^{34}$ El monto asignado sería de diez mil colones, el cual se incrementaría según el costo de la vida. Sin embargo, poco tiempo después -específicamente, en 1992-, esta normativa fue revocada por medio de la Ley $\mathrm{N}^{\circ} 7302$, artículo $41^{\circ}$. En ese mismo año, otro revés que sufrieron especialmente los artistas fue la derogación de todas las exenciones tributarias indicadas en leyes, decretos y normas legales, que se promulgó en la Ley $\mathrm{N}^{\circ} 7293$ (artículo $1^{\circ}$ ). Esto significó la revocación de las exoneraciones de impuestos definidas en la Ley de Estímulo a las Bellas Artes Costarricenses ( $\mathrm{N}^{\circ}$ 6750). Otros tiempos se avecinaban; el Estado por momentos se alejaba de su papel de mecenas.

Pareciera que como compensación a las anteriores normativas, se promulgó la Ley $\mathrm{N}^{\circ}$ 7345, en 1993, concerniente a los premios nacionales de cultura. El cambio que se dispuso en esta ley consistió en eliminar un monto fijo otorgado como galardón y sustituirlo por lo establecido en la escala salarial de la Administración Pública. En el caso del favorecido con el Premio Magón, este obtendría el equivalente de diez salarios base de un Profesional 3 y, en el del Premio “Aquileo J. Echeverría”, ocho salarios base de un Profesional 3. Esto implicaba sumas que variarían según los aumentos salariales establecidos a dichas categorías. Es decir, cabía la posibilidad de que los montos asignados a los premios se incrementaran y no quedaran fijos y, por ende, devaluados con el paso del tiempo. En realidad, los artistas se vieron sustancialmente beneficiados con las mejoras fijadas en los premios nacionales. Aunque el número de creadores que las disfrutarían sería mínimo en relación con la totalidad de estos, su cantidad sería mayor que los que gozaron de las exenciones tributarias, pues prácticamente no existían asociaciones de artistas.

$34 \quad$ Oficial, Colección de leyes y decretos, I Semestre, I Tomo (San José, Costa Rica: edición oficial, Imprenta Nacional, 1985), 109. 
Un aspecto que el Estado procuró continuar fue el debido mantenimiento de los museos ya establecidos. En este período, se promulgaron normativas que reforzaron leyes y decretos ejecutivos -emitidos en las décadas anteriores- relacionados con impuestos que beneficiaban a dichas instituciones. Por ejemplo, en el Decreto Ejecutivo No 23642 (1994), se determinó una reforma al reglamento de la ley que definió un impuesto a la presentación de artistas extranjeros del espectáculo a favor del Museo de Arte Costarricense (Decreto Ejecutivo No 13600-C-G, 1982). A este se le adicionaron varios artículos; uno quedó consignado como el artículo $9^{\circ}$, el cual señaló esto: "Los fondos que se recauden por concepto del impuesto, serán utilizados por el Ministerio de Cultura, Juventud y Deportes en el financiamiento de actividades culturales del Museo de Arte Costarricense a tenor de la Ley No 5812 del 10 de octubre de 1975.”35

En realidad, el Estado ha mantenido un sustento económico continuo para instituciones como los museos; algunos han contado con un presupuesto amplio y otros solo con el pago de salarios y servicios. Aunque los encargados de estas instituciones han considerado insuficiente este apoyo, por lo menos sus necesidades básicas para operar han sido cubiertas. Por lo tanto, a partir de esta base esencial, los museos han tenido que buscar mayores ingresos para poder ejecutar sus proyectos y responder a los requerimientos de sus respectivos públicos, razón por la cual han debido recurrir a patrocinadores privados. ${ }^{36}$

\section{Entre el proteccionismo estatal y la autogestión (2000-2005)}

Si en la década de 1990 el Estado mantuvo normativas que sustentaron entidades culturales como los museos, en el primer quinquenio del 2000 continuó en igual línea. Aunque se promulgaron leyes que aparentemente representaban recortes a los presupuestos de dichas instituciones, estas mismas contenían la compensación. En relación con la ley que regulaba la contratación e impuestos a artistas extranjeros del espectáculo ( $\mathrm{N}^{\circ}$ 5812), se promulgó la Ley de Simplificación y Eficiencia Tributaria No 8114 -en el 2001- que derogó dicho tributo. En el artículo $31^{\circ}$, inciso g, se suprimió el impuesto a la promoción de las actividades artísticas, el cual había sido establecido en los artículos $2^{\circ}$ y $5^{\circ}$ de la Ley $\mathrm{N}^{\circ}$ 5812. Igual destino sufrió la ley encargada de gravar los pasajes aéreos internacionales ( $\mathrm{N}^{\circ} 5351$ ), es decir, el llamado Timbre del Museo Nacional, cuyo monto era repartido entre varias instituciones culturales. En el 2002, se emitió la Ley Reguladora de los Derechos de Salida del Territorio ( $\mathrm{N}^{\circ}$ 8316), en la cual se suprimieron las anteriores disposiciones tributarias respecto al derecho de salida del territorio 35 Base de datos Sistema Costarricense de Información Jurídica.

36 Herrero, 86. 
nacional y se establecieron nuevos beneficiarios.

A pesar de lo anterior, en ambas derogaciones se incluyeron medidas que contrarrestaban el impacto de este recorte de fondos. Tanto la Ley N No 8114 como la № 8316 incorporaron artículos similares al que aparece en el artículo $8^{\circ}$ de esta última normativa:

"El Poder Ejecutivo, por medio del Ministerio de Hacienda, podrá incorporar, únicamente en el presupuesto ordinario y extraordinario de la República siguiente a la aprobación de esta Ley y dentro de las limitaciones fiscales existentes, los ingresos que las entidades beneficiarias dejarán de percibir por la eliminación de los tributos indicados en la presente Ley...”37

En realidad, según el ex subdirector del Museo de Arte Costarricense, Ricardo J. Méndez Alfaro, la supresión de los impuestos antes mencionados no afectó a la Institución, pues justamente estos se compensaron con los recursos asignados en los presupuestos ordinarios y extraordinarios para tal fin. ${ }^{38}$

A pesar de las condiciones circundantes o internas del Estado costarricense, este ha mantenido un apoyo constante a las entidades culturales por medio de la promulgación de normativas y, además, a lo largo del tiempo le ha dado continuidad a estas. Por ejemplo, leyes o decretos ejecutivos emitidos en los años de 1960 han sido retomados en las décadas siguientes. Un caso es las Becas Taller, definidas en el Reglamento de la Dirección General de Artes y Letras, según lo establecía el Decreto Ejecutivo Nº 33 en 1969. En los 35 años siguientes, dichas becas fueron retomadas en diversas normativas.

Otro caso similar al anterior parte de la ley de creación del Museo de Arte Costarricense ( No 6091), promulgada en 1977. Específicamente, desde la disposición de que el Museo fuera la entidad encargada de decidir sobre la adquisición de obras de arte con fondos del Estado (artículo $2^{\circ}$ ), se emitieron otras normativas relacionadas. Respecto a esto, el Estado revelaba un interés por sostener los esfuerzos y avances mantenidos hasta el momento.

En realidad, el Estado mantuvo un rumbo similar en cuanto a la promulgación de normativas; sin embargo, sí se dio una disminución en cuanto a la cantidad que se emitieron y la intensidad de la fundamentación de su contenido. En el Decreto Ejecutivo No 28606-G -publicado en el

$37 \quad$ Oficial, La Gaceta, 24 de octubre 2002, 2.

38 Conversación informal entre Ricardo J. Méndez Alfaro y Eugenia Zavaleta Ochoa. San José, Costa Rica: 12 de febrero 2008. 
2000-, se retomó el tema de la Escuela Casa del Artista. Este determinó reformas al Decreto Ejecutivo $\mathrm{N}^{\circ}$ 27988-C, promulgado en 1999. Una de las modificaciones consistió en ampliar los destinatarios en que se enfocaba la Escuela y el campo de estudio, pues se orientó a los diferentes sectores de la población y a las artes plásticas y la artesanía.

Otra institución a la que se le dio seguimiento fue al Museo de Formas, Espacios y Sonidos (MUFES). Con el Decreto Ejecutivo No 32023, se estableció la creación de esta entidad, en el 2004. También la intención de esta normativa fue extender el posible público visitante del Museo; en general, se incorporaría a todas las personas con discapacidades.

Durante el primer quinquenio del 2000, prevaleció la idea de que el Estado debía apoyar y promocionar las artes. Esto se aprecia en dos reglamentos -vigentes a partir del 2003-, que normaban el montaje de las exposiciones en la galería del vestíbulo del Teatro 1887 del Centro Nacional de la Cultura y las Galerías José Luis López Escarré y Joaquín García Monge, del Teatro Nacional. En el primero (Decreto Ejecutivo $N^{\circ}$ 30923), el considerando inicial evidencia la visión antes mencionada: "Que el Ministerio de Cultura, Juventud y Deportes, es la entidad encargada de estimular la creación artística en sus diferentes manifestaciones, ofreciendo a sus exponentes la mayor cantidad de oportunidades para el desarrollo de sus capacidades." ${ }^{39}$

Un aspecto más que se recuperó fue el discurso en relación con la identidad cultural. En realidad, este ya no se emitía en forma intensa y sistemática, pues simplemente aparecía como una lejana y débil resonancia de los años de 1990. La alusión al respecto se produjo en el Decreto Ejecutivo No 27993 (2000), relativo al Colegio de Costa Rica. Cinco años después, se emitió otro decreto ejecutivo ( $\mathrm{N}^{\circ}$ 32740) sobre este, en el cual se hacían referencias similares.

Un discurso muy similar sobre la identidad cultural volvió a aparecer, cuando -en el 2005- se determinó el establecimiento del Museo Histórico de la Ciudad de Puntarenas (Decreto Ejecutivo No 32510) y el Museo de Guanacaste (Decreto Ejecutivo No 32531). Sin embargo, sí se dieron diferencias; una fue un descenso considerable en la cantidad de museos fundados en el primer quinquenio del 2000 en relación con los de la década de 1990; aparentemente, entre el 2000 y 2005 solo se fundaron estos dos museos. Otra divergencia consistió en la nueva posición que asumieron en cuanto a su gestión administrativa. En ambos museos -con algunas variantes-, se indicó la disposición de impulsar la autogestión y el financiamiento propio.

Por consiguiente, se evidencia claramente la inclinación por diluir cada vez más el papel 
del Estado Benefactor como mecenas y soporte económico de entidades culturales. En esta misma dirección, ya se habían encauzado los Museos del Banco Central de Costa Rica. A partir del 2000, este camino se enfatizó, por ejemplo, con el Decreto Ejecutivo № 28497-C, en el cual se declaró de interés cultural el proyecto "Remodelación del Museo del Oro Precolombino" de dicha entidad. Una de las justificaciones para llevar a cabo este trabajo se basó en el potencial que representaba el turismo cultural para generar recursos monetarios.

Asimismo, se emitieron modificaciones y una nueva versión de las "Normas generales para la coordinación en la administración de los Museos del Banco Central de Costa Rica” (Reglamento $\mathrm{N}^{\circ}$ 5044). Con esto, se afianzaba la Fundación en la administración de dicha institución; sin embargo, el Banco mantenía una cierta injerencia. Estos son ejemplos de cómo el Estado ha cedido espacio a entidades privadas, pero aun así se resiste a eliminar por completo su papel de mecenas; de esta manera, se aferra a conservar su presencia en la dinámica cultural del país.

\section{Balance}

La estructura legal que a finales de la década de 1950 comenzó a construirse con leyes, decretos ejecutivos, reglamentos y resoluciones conformó un esqueleto de políticas culturales que contribuirían con el desarrollo del campo cultural y, a su vez, con el mercado de arte costarricense. Esta matriz de normativas inició con una preponderancia hacia las letras y los escritores; sin embargo, en forma de rebote alcanzó finalmente a las demás disciplinas artísticas. Las iniciativas culturales que se impulsaban desde el marco legal llevaban implícitas el interés por dar a conocer a los artistas, abrirles espacios para desarrollar su labor, destacarlos y, especialmente, configurarles una reputación. Para alcanzar este propósito, el Estado se posicionó como promotor y mecenas de las artes.

El siguiente paso que el Estado dio - en los años de 1970- como protector de las artes y de la cultura, en general, consistió en crear instituciones que apoyaran el desarrollo de las diversas disciplinas artísticas. Para lograrlo, respaldaron dichas iniciativas con normativas que estipulaban ya fuera la asignación de presupuestos o el establecimiento de impuestos para darle sustento económico a las recién fundadas entidades. Asimismo, se aseguraron contar con edificaciones que las albergaran; es decir, se cuidaron todos los flancos. Además, se empezaron a generar las bases legales que contribuirían con el desenvolvimiento de un mercado de arte y se continuaron las relacionadas con prestigiar la figura de los artistas, especialmente, los dedicados a las artes visuales. 
Aunque, durante la década de 1980, Costa Rica vivió la presión de organismos financieros internacionales para disminuir el gasto público, el Estado no derogó normativas que justamente implicaban desembolsos. Más bien, las leyes y decretos -emitidos en el decenio anterior- que habían favorecido a los museos y a otras entidades culturales fueron reforzados y consolidados con nuevas normativas o reformas. Así, el Estado no desistió de continuar como mecenas y protector de las artes. En realidad, la representación de este papel le creaba una imagen de prestigio de la cual no podía prescindir.

En el siguiente decenio, se dio una proliferación de nuevos museos, lo cual quedó patente en una profusa cantidad de normativas. Sin embargo, los museos más grandes y antiguos del Valle Central fueron los que generaron leyes y decretos ejecutivos más complejos y en forma sistemática, tal fue el caso del Museo Nacional, el Museo de Arte Costarricense y los Museos del Banco Central de Costa Rica. Este mismo camino seguiría el Museo de Arte y Diseño Contemporáneo. También, en este período el Estado procuró promulgar normativas que lo descargaran del soporte económico brindado a instituciones y de disposiciones relacionadas con el arte. Al igual que diez años antes, esto no llegó a concretarse; el mismo Estado se las agenció para compensar los recortes presupuestarios o ayudas financieras que le brindaba a los artistas y a las entidades culturales. Aun más, esta línea de apoyo se mantuvo en el quinquenio 20002005; no obstante, cabe señalar que su intensidad disminuyó y comenzó a tener una mayor presencia las fundaciones privadas y un espíritu a favor de la autogestión de las instituciones. Sin duda, los vestigios del Estado Benefactor todavía resollaban en el mundo de los artistas y los establecimientos culturales, aunque pareciera que cada vez su volumen va haciéndose un poco menos audible. En todo caso, el Estado había definido una política cultural por medio de la promulgación de normativas, las cuales se convirtieron en el fundamento que permitió el desarrollo y florecimiento de un pujante mercado de arte. 